\title{
Antigüedad clásica y ciudad: de la arqueología al mundo de la fiesta renacentista
}

\author{
Vicente lleó Cañal *
}

Desde el siglo $x v$ en toda Europa, una de las principales ocupaciones de los humanistas va a ser la elaboración de fantásticas genealogías de las ciudades en las que prestan sus servicios. Estas laudes storiae patriae refieren con delectación su fundación por dioses o héroes míticos y generalmente describen un pasado en el que la ciudad en cuestión disfrutó de una posición bastante más exaltada que en el momento presente.

Estas genealogías locales, pese a la manipulación o falsificación directa de los datos históricos merecen una atención mayor de la que se le ha venido prestando, pues a través de su estudio podemos entrever algo del funcionamiento del imaginario social, de las ansiedades y aspiraciones de sus gentes ${ }^{1}$. Con todas las matizaciones y salvedades que quieran hacerse parece innegable que en términos amplios los hombres del Renacimiento tuvieron una visión crítica de su pasado medieval. Esta actitud que podemos remontar a Francesco Petrarca o incluso a Cola di Rienzi suponía una radical inversión del concepto de la Civitas Dei agustiniana y sin duda podemos atribuir a esa circunstancia la moderación con que en general expresaron su visión negativa del pasado más reciente. Pero, en cualquier caso, la reivindicación del pasado clásico implicaba casi ineludiblemente la depreciación del más inmediato que si en el caso italiano aparecía teñido de barbarie "gótica" o "tedesca", en el español acumulaba a ello la contaminación morisca ${ }^{2}$.

* Escuela Técnica Superior Arquitectura. Sevilla.

1 Cf. Frugoni, C., "L'antichitá: dai Mirabilia alla propaganda politica", en AA.VV., Memoria dell 'antico nell'arte italiana. Turín 1984.

2 Sobre la ambivalente, aunque a la larga mayoritariamente negativa, actitud de los españoles a lo musulmán, a lo largo del siglo xvI, cf. las recientes páginas de MARías, F., El largo siglo xvı. Madrid 1989, págs. 181 ss. 
Ahora bien, la reivindicación del pasado clásico, del mundo romano, en los inicios de la Era Moderna no obedecía a un mero gusto «anticuario»; implicaba al mismo tiempo reivindicar el momento de mayor esplendor de la vida urbana, de la que eran elocuentes testimonios los restos monumentales y epigráficos esparcidos por las ciudades del antiguo imperio, no menos que los propios testimonios literarios.

Para los humanistas del Renacimiento, entendiendo ese término en su sentido más amplio, la arqueología no era una ciencia aséptica, sino un instrumento operativo capaz de recomponer, de suturar el tejido social y urbano roto tras la gran crisis de las ciudades entre los siglos $\vee$ y XIII. $Y$ ello no sólo en sus aspectos figurativos o formales: cuando Cola di Rienzi, por ejemplo, instala en el palacio de Letrán la Lex Vespasianus que había sido escondida por Bonifacio VIII, no lo hace por su amor a los monumentos epigráficos, sino como un símbolo de los antiguos valores y libertades cívicas que habían sido usurpadas por la autoridad, en definitiva medieval, del papado ${ }^{3}$.

La antigüedad clásica no es, pues, o no es sólo, el mundo de las ensoñaciones erótico-anticuarias de Polifilo, en la hermosa novela atribuida a Francesco Colonna, sino también un poderoso vehículo para dar forma al presente, para recuperar, en todo el sentido de la palabra, la «urbanidad» perdida durante siglos de barbarie. El fenómeno al que aludíamos al principio de estas líneas, la elaboración de fantásticas genealogías locales, es, pues, inseparable del pujante resurgir contemporáneo de las ciudades.

Ahora bien, el proyecto de enlazar a través del tiempo con un glorioso pasado, de recomponer los eslabones rotos en el devenir histórico contrastaba con el misérrimo estado físico de la mayoría de las ciudades al inicio de la Era Moderna. Sevilla, por ejemplo, aparece en 1495 a los ojos del viajero alemán Jerónimo Münzer como una ciudad todavía fundamentalmente musulmana ${ }^{4}$. $Y$ pese al intenso esfuerzo de "policía urbana» desplegado por las autoridades a lo largo del siglo, grandes sectores de las ciudades debieron conservar una configuración medieval. La propia inercia de la ciudad construida constituyó el principal obstáculo para los planes de renovatio que con mayor o menor intensidad se plantearon las ciudades durante el Renacimiento y elló obligaría a definir un conjunto de estrategias.

3 Frugoni, C., op. cit., pág. 16.

4 Apud García Mercadal, J., Viajes de Extranjeros por España y Portugal (Madrid, 1952 vol. I, pág. 372). 
Un ejemplo singular de esta actitud lo constituyen las invenciones y tergiversaciones históricas del Bachiller Luis de Peraza en su sólo parcialmente editada Historia de Sevilla, escrita hacia 1535, cuyo transfondo lo forma un vigoroso alegato pro translatio imperii ${ }^{5}$. Peraza pasa como sobre ascuas por el bien visible pasado musulmán de la ciudad, concentrándose por el contrario en su glorioso pasado clásico y en su pujante presente auspiciado por el oro de Indias. Característico de esta actitud es el relato que inserta sobre la Catedral hispalense. Según Peraza ésta había sido fundada por el Apostol Santiago, quien la nombró Sacrosancta Jerusalem, aunque luego a causa de los milagros que se sucedieron en su entorno esta denominación fue ampliada a Sacrosancta Celestial Jerusalem; tras la «destrucción» de España por la invasión musulmana el mismo templo habría sido transformado en mezquita y ahora, añade, "los santos arzobispos... con acuerdo del mui reverendo capítulo suio, desaciendo las obras que de tiempos de moros en el estaban han hecho otras de mayor suntuosidad, fundándolas todavía sobre el antiquisimo suelo que siempre fue uno..." ${ }^{6}$.

Para Peraza, por lo tanto, la enorme mole de la Catedral gótica sería antes que nada una "restauración» de la Sacrosancta Celestial Jerusalem del pasado, una vez borradas las huellas «de tiempos de moros". Lo más curioso es que tan extravagante opinión, aunque de modo difuso, parece haber estado bastante extendida incluso entre eruditos de los que cabría esperar mayor rigor. Así, por ejemplo, Alonso de Morgado, refiriéndose al alminar almohade de la Catedral sevillana, la Giralda, afirma que «algunos de nuestros más curiosos arquitectos no acaban de persuadirse que un edificio tan alto, tan fuerte, tan suntuoso y magnífico como esta famosa Torre de Sevilla, sea obra de moros, sino que es de muy antes, del tiempo de gentiles...” ${ }^{7}$. Morgado publicó su libro en 1587, pero ya antes, en 1555, el pintor flamenco afincado en Sevilla Hernando de Sturmio había ilustrado esta peregrina teoría representando a la Giralda almohade en un conjunto de ruinas clasicistas aparentemente inspiradas en la Basilica de Majencio, entre las Santas Justa y Rufina del retablo de los Evangelistas $^{8}$ (fig. 1). La intervención de Hernán Ruiz, sólo tres años posterior

5 Sobre el sentido de la obra de Peraza, cf. Lleó Cañal, V., Nueva Roma: mitologia y humanismo en el Renacimiento sevillano. Sevilla 1979, págs. 176 ss.

${ }_{5}$ Cf. la edición parcial titulada Historia de Sevilla por Luis de Peraza a cargo de F. Morales Padrón. Sevilla 1979, págs. 38 ss.

7 Morgado, A., Historia de Sevilla... Sevilla 1587, pág. 91.

a Cr. Serrera, J.M., Hernando de Esturmio (Sevilla 1983), pág. 96. La composición arquitectónica es en realidad un capriccio donde se mezclan libremente elementos de diversa procedencia, como un pórtico de hermes junto a las bóvedas que identificamos con la Basilica de 


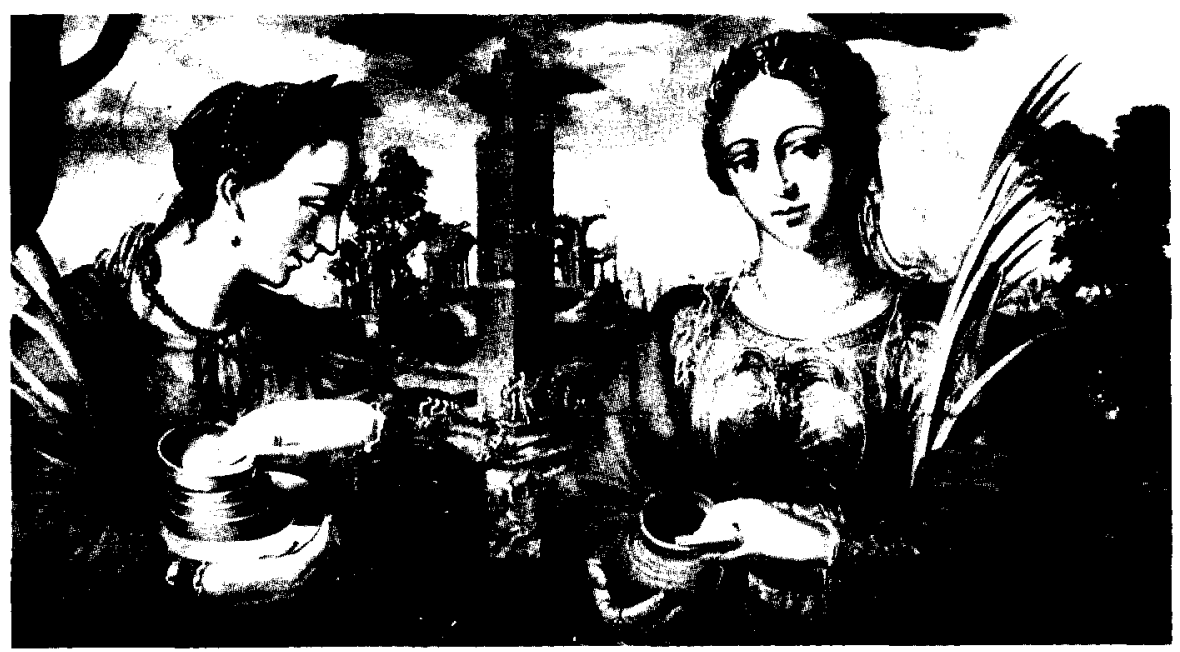

Fig. 1. Hernando de Sturmio, "Santas Justa y Rufina». Retablo de los Evangelistas. Catedral de Sevilla.

al retablo de Sturmio, que le daría a la Giralda su configuración actual puede entenderse en este contexto como otra "restauración".

Los ejemplos de este tipo de intervenciones en las que la Arqueología o las formas clásicas adquieren un valor instrumental destinado a devolver a las ciudades, aunque sea analógica o alegóricamente, su estado primitivo pueden multiplicarse: desde decorados efímeros, con ocasión de las visitas reales, que permitían enmascarar la ciudad contemporánea bajo galas «romanas", hasta intervenciones puntuales de carácter emblemático. Dejando a un lado las primeras que están siendo objeto de creciente interés y estudio me gustaría centrarme en dos ejemplos de intervenciones puntuales, extraordinariamente ricas en matices, dentro de la arquitectura del Renacimiento en Andalucía.

En 1577 y a instancias del Gobernador y Justicia Mayor de esta provincia de la Orden de Calatrava, don Pedro de Aboz y Enriquez, la ciudad de Martos tomaba el acuerdo de labrar nuevo edificio para Cabildo y Cárcel. Martos había sido particularmente fecunda en este género hu-

Majencio. En la tabla compañera del mismo retablo, con Santa Catalina y Santa Bárbara, por su parte, se distingue claramente en el ángulo izquierdo el Septizonium y un obelisco. Aunque Esturmio, desde luego, pudo conocer estos monumentos por grabados, tampoco cabe descartar una breve estancia en Roma antes de su llegada a Sevilla. 


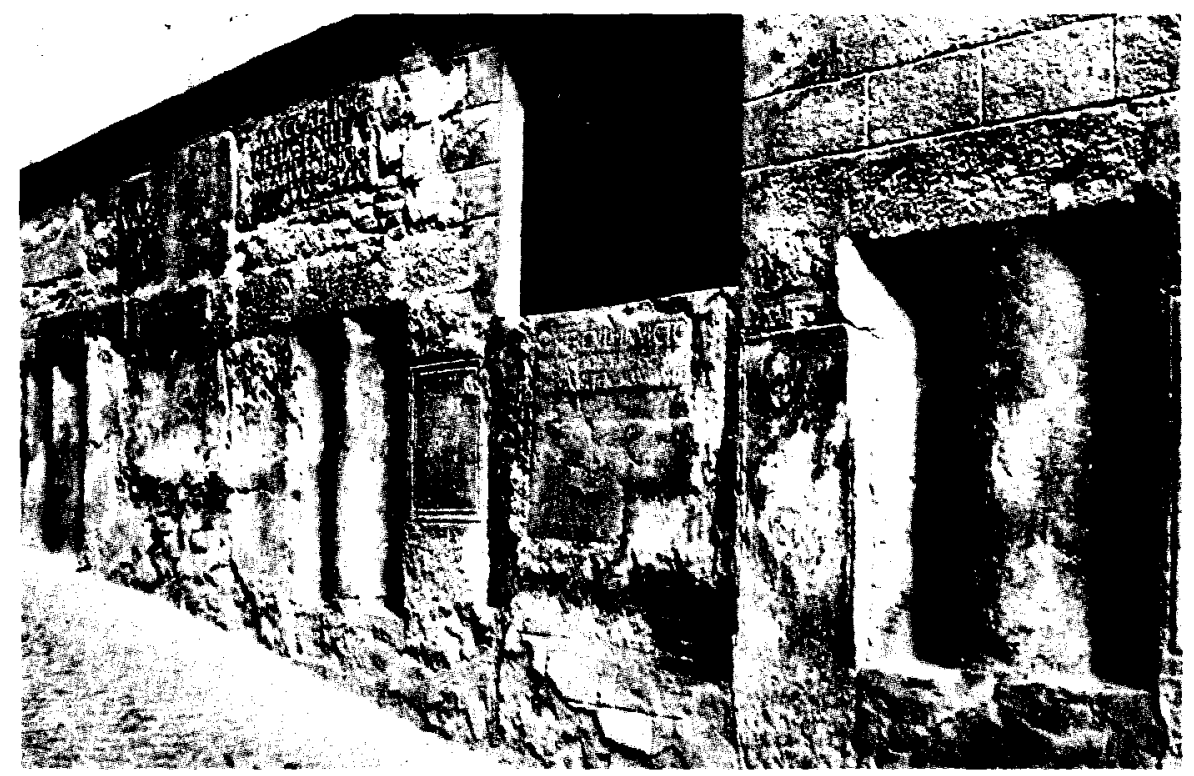

Fig. 2. Francisco del Castillo. Fachada lateral de la Cárcel y Cabildo de Martos (Jaén).

manístico al que aludíamos páginas atrás de genealogías locales. Ya en el primer cuarto del siglo xVI, Francisco Delicado en su novela titulada $\mathrm{La}$ Lozana Andaluza (Venecia 1528) había trazado sus remotos orígenes, afirmando que "(Martos) es una villa cercada y cabeza de maestrazgo de Calatrava y antiguamente fue muy gran ciudad, dedicada al dios o planeta Marte... que aquella peña era su trono y ara de donde tomó nombre la Peña de Marte y al presente de los Martos...» añadiendo más adelante «en aquella tierra hay las señales de su antigua grandeza en abundancia ... dicen que antiguamente se decía Roma la Vieja” " ${ }^{9}$.

Todos los elementos del mito urbano, recogidos y ampliados en 1570 por Diego de Villalta, aparecen ya aquí con la mayor claridad: la fundación mítica, la antigua grandeza de la ciudad, su conexión, en fin. con Roma... El edificio levantado por Francisco del Castillo a partir del acuerdo tomado en 1577 busca traducir a términos visuales la conexión entre tan exaltado

9 Delicado, F., La lozana andaluza (ed. B. Damiani. Madrid 1969) págs. 187 ss 
pasado y un optimista presente en la visión de un corregidor «ilustrado». Así, la fachada que da a la plaza, con su arquitectura serliana y sus esculturas alegóricas, expresa la "nueva" Antigüedad, renacida tras los siglos de barbarie, mientras que la fachada lateral con su extraordinario collage de sabor casi piranesiano de fragmentos e inscripciones latinas se configura por el propio desnivel de la calle como el basamento o sustrato, tanto en sentido literal como literario, del nuevo edificio. Antigüedad "nueva" y Antigüedad "antigua» aparecen así estrechamente asociadas, por encima del tiempo y del espacio ${ }^{10}$ (fig. 2).

Otro ejemplo de lo que podríamos denominar "usos de la Antigüedad" y no menos rico en matices que el Cabildo de Martos lo encontramos en la construcción en Sevilla del Paseo de la Alameda entre 1574 y 1578. La obra, realizada a instancias del Asistente de la ciudad Francisco Zapata de Cisneros, Conde de Barajas, tenía por objetivo principal desecar una pestilente charca, resto de un brazo del Guadalquivir, conocida popularmente como la Laguna, transformándola de un paraje insalubre en un "civilizado" lugar de esparcimiento, con sus fuentes monumentales y las dos columnas rematadas por las estatuas de Hércules y Julio César. Estas efigies representaban, en realidad sub specie classica al Emperador Carlos y a su hijo Felipe II, como dejan bien claro las inscripciones añadidas en las bases; pero nos interesa más destacar otra inscripción, añadida por acuerdo capitular, en que se hace constar la gratitud al Asistente «por haber transladado hasta aquí las columnas de Hércules con un trabajo comparable a los del mismo Hércules" ${ }^{11}$ (fig. 3).

La conexión no era gratuita; en efecto, las columnas que tan trabajosamente fueron transladadas hasta la Alameda (hubo que romper para ello un lienzo de muralla, junto a la Macarena) procedían de los restos de un templo romano junto a la parroquia de San Nicolás, donde aún se conservan tres fustes (otro se partió en tiempos del Rey Pedro I, según la tradición, cuando se le transladaba hacia el Alcázar). En una reunión de humanistas, entre los que se encontraban Benito Arias Montano, Juan de Mal Lara, Francisco de Medina, etc., que habían acudido a ver el traslado de los mármoles surgió la discusión sobre a quién podía haber estado dedicado este templo. El relato, contenido en un manuscrito de la Biblioteca Nacional ${ }^{12}$ recoge la conclusión unánime, por motivos eruditos,

10 Galera Andreu, P., Arquitectura y arquitectos en Jaén a fines del siglo xvi (Jaén 1982), págs. 81 ss.

11 La lápida latina y su traducción en PALOMO, F. de B. Historia critica de las Riadas o grandes avenidas del Guadalquivir en Sevilla. Sevilla 1878, pág. 199

12 Catálogo de los Arzobispos de Sevilla. Madrid, Biblioteca Nacional, Ms. 1419 


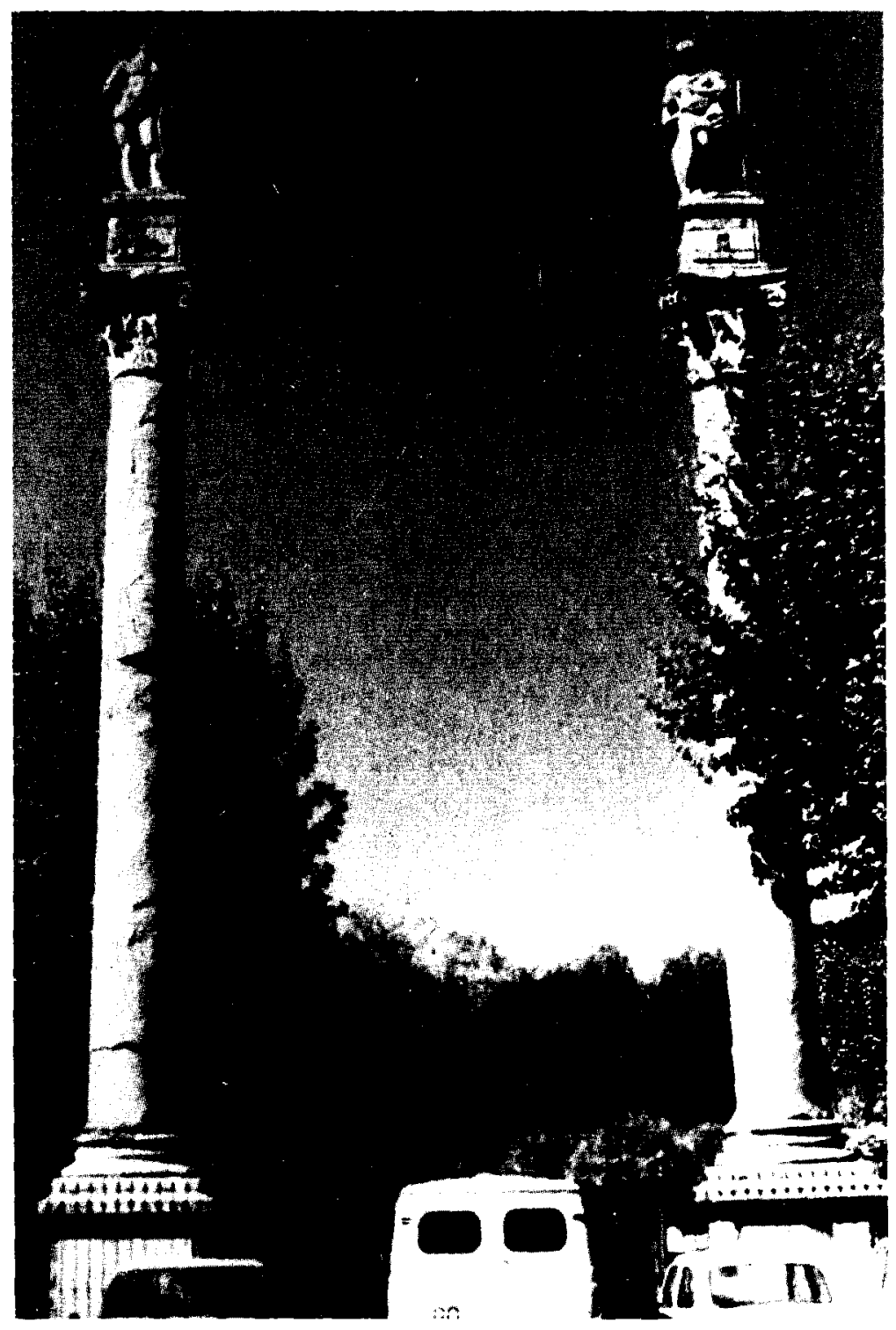

Fig. 3. Alameda de Hércules, Sevilla. Columnas romanas con las estatuas de Hércules y Julio César. 

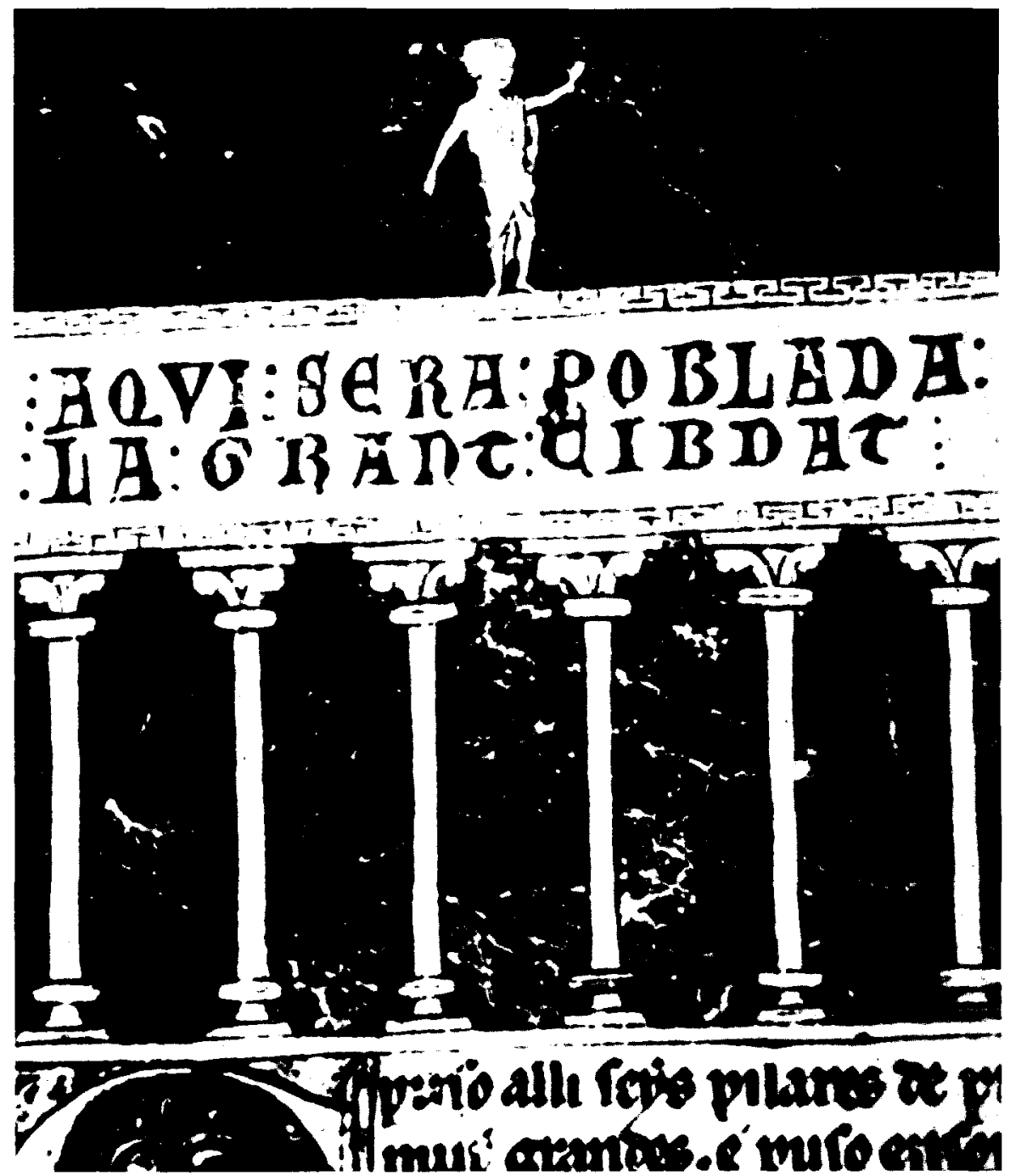

Fig. 4. Columnas de Hércules. Primera Crónica General, Biblioteca Escurialense.

de que esta deidad hubo de ser Hércules. Sin embargo, la tradición que vinculaba los mármoles de la parroquia de San Nicolás con Hércules venía de más lejos. En efecto, en una miniatura de la «Primera Crónica General», realizada en el scriptorium de Alfonso $X$ podemos ver el hito fundacional levantado por Hércules donde más tarde Julio César habría de poblar a Sevilla (fig. 4). Se trata de un pórtico hexástilo, rematado por un entabla- 
mente con la inscripción "aquí será poblada la grant cibdat" y una estatua de Hércules encima ${ }^{13}$. Parece más que probable que la inspiración del miniaturista alfonsino debió ser el pórtico del templo junto a San Nicolás, que entonces mantenía aún su frente hexástilo en pié. Al tomar dos de estos mármoles, no ya de un templo dedicado a Hércules, sino levantados por el propio Hércules, el Asistente Conde de Barajas mimetizaba la acción civilizadora del héroe mítico, "refundando" un espacio antes desierto y abandonado.

Significativamente, la actitud del Conde de Barajas quien osaba de este modo emular al héroe tebano e incluso colocar una inscripción referida a si mismo junto a las de los monarcas fue objeto de la hostilidad popular ${ }^{14}$. Ahora bien, a mi juicio, esta actitud de rechazo hay que enmarcarla en la general reacción antihumanista, en contra de los saberes clásicos y en defensa de los valores "castizos" que resulta cada vez más perceptible a lo largo de la segunda mitad del siglo XVI. Es este un tema que ha suscitado poco interés entre los investigadores pero creo que los síntomas de la nueva actitud de la sociedad son abundantes y en campos muy diversos. Así, por ejemplo, aunque me temo que sólo puedo afirmarlo de un modo intuitivo, la famosa polémica entre los «buenos y los malos poetas" que agitó la Sevilla de finales del siglo y que nos ha dejado testimonios como la "Sátira contra los malos poetas" del canónigo y licenciado Francisco Pacheco o las "Observaciones..." contra Fernando de Herrera del autodenominado Prete Jacopín creo que encubre no un mero enfrentamiento entre dos tendencias o escuelas poéticas locales, sino entre lo que podríamos denominar dos horizontes o niveles culturales radicalmente antagónicos: uno que hunde sus raices en el mundo y las formas expresivas clásicas y el otro visceralmente castizo ${ }^{15}$.

Como ya he señalado en otra ocasión, este "cerrarse" de España, con la consiguiente exaltación de los valores tradicionales, llegarían a convertir a la cultura humanista en algo semi-clandestino, oscilando entre las divagaciones eruditas, radicalmente minoritarias, casi esotéricas y la frivolidad evasiva de tantas «academias" poéticas con sus ficciones pastoriles y sus seudónimos clasicistas ${ }^{16}$.

\footnotetext{
13 Reproducido en Gómez Ramos, R., “La visión de la Antigüedad en las miniaturas de la Primera Crónica General», en Homenaje al Dr. Muro Orejón. Sevilla 1979, vol. I.

14 Lleó Cañal, V., Nueva Roma..., cit., pág. 197.

15 Sobre esta polémica, cf. el ensayo titulado, "Críticos, critiquillos y criticones (Herrera el sevillano frenta a Sevilla)", en VRANICH, S.B., Ensayos sevillanos del Siglo de Oro. Valencia 1981.

16 Cf. Lleó CAÑAL, V., "La conjoncture classique dans la sculpture sevillaine: les années $1570 \%$, en Revue de l'Art (70), 1985
} 


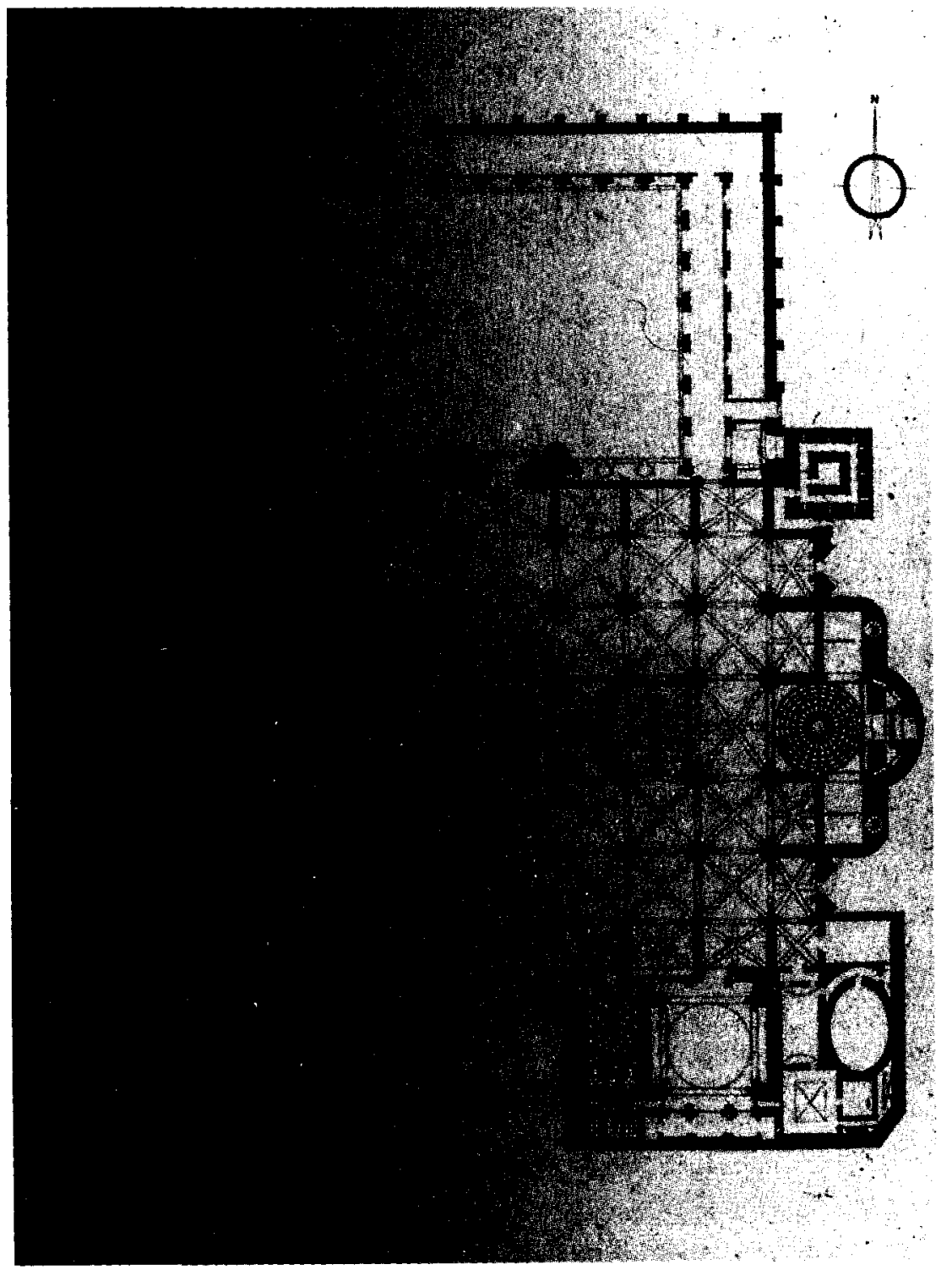

Fig. 5. Catedral de Sevilla. Planta. (De AA.W., "La Catedral de Sevilla»). 


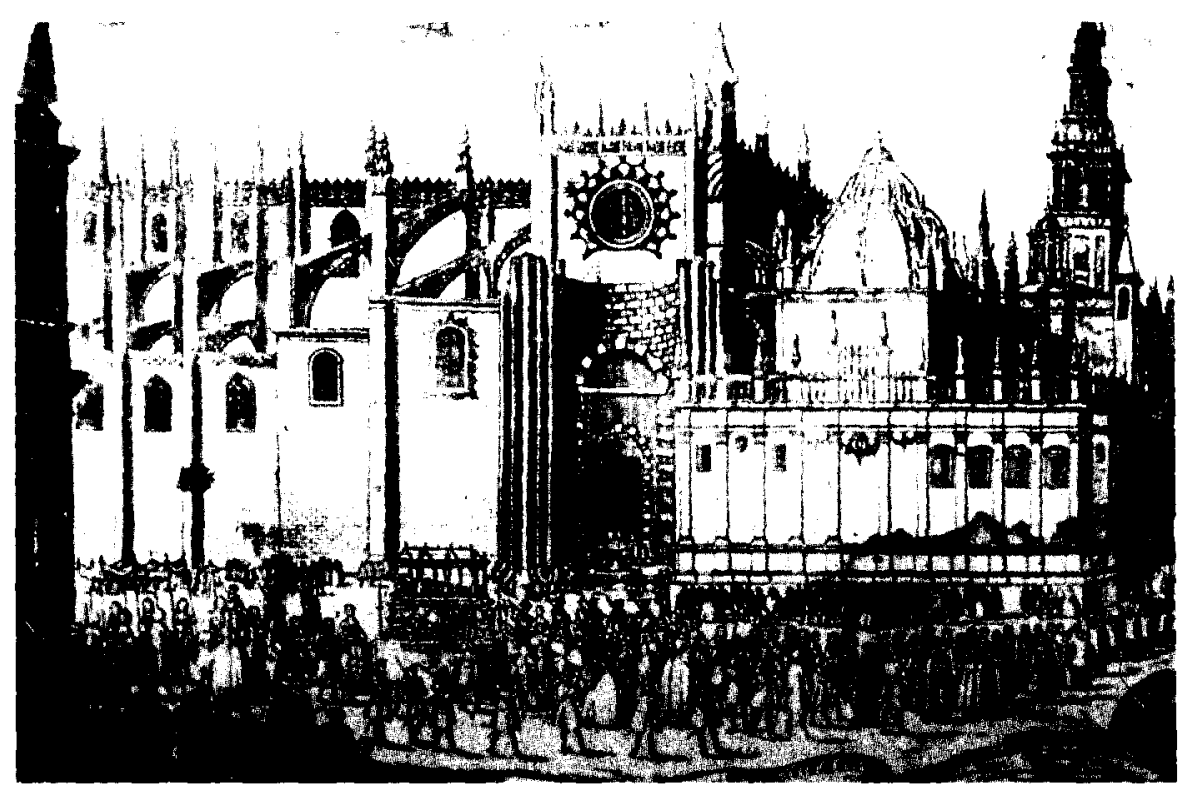

Fig. 6. P. Tortolero (atrib. a). Procesión con el Cuerpo de San Fernando, mostrando el flanco Sur de la Catedral de Sevilla.

Sin embargo, en ocasiones creemos percibir un hálito distinto en este mundo del humanismo tardío; como un empeño trágico en mantener pese a todo y aun a costa de renunciar a cualquier manifestación externa, la validez de unos principios universales. Este es sin duda el caso de una de las más singulares empresas arquitectónicas en la Sevilla del Quinientos: el conjunto de estancias capitulares de su Catedral. Situadas en el flanco sur de la mole gótica y ocultas a la mirada del viandante por un alto muro ${ }^{17}$ (figs. 5, 6), los problemas de toda índole -autor, cronología, interpretación iconográfica, etc.- que plantea (y que desde luego no aspiramos a resolver aquí) han contribuido a su general desconocimiento.

Las estancias capitulares ocupan el extremo este de un conjunto de edificaciones, situadas entre las puertas de San Cristóbal y de las Cam-

17 No sólo ocultas desde el exterior sino de muy difícil acceso incluso desde el interior. Así, Torre Farfán, F. de la, en sus Fiestas de la Sta. Iglesia... al nuevo culto del señor Rey $S$. Fernando... Sevilla 1671, destaca como cosa notable que «Esta Gran Pieza (la Sala Capitular) estuvo, por todo el tiempo de aquellos días, sin su perpetua Clausura; manifiesta entonces a quantos quisieron hartar los Deseos de su Hermosura", pág. 204. 


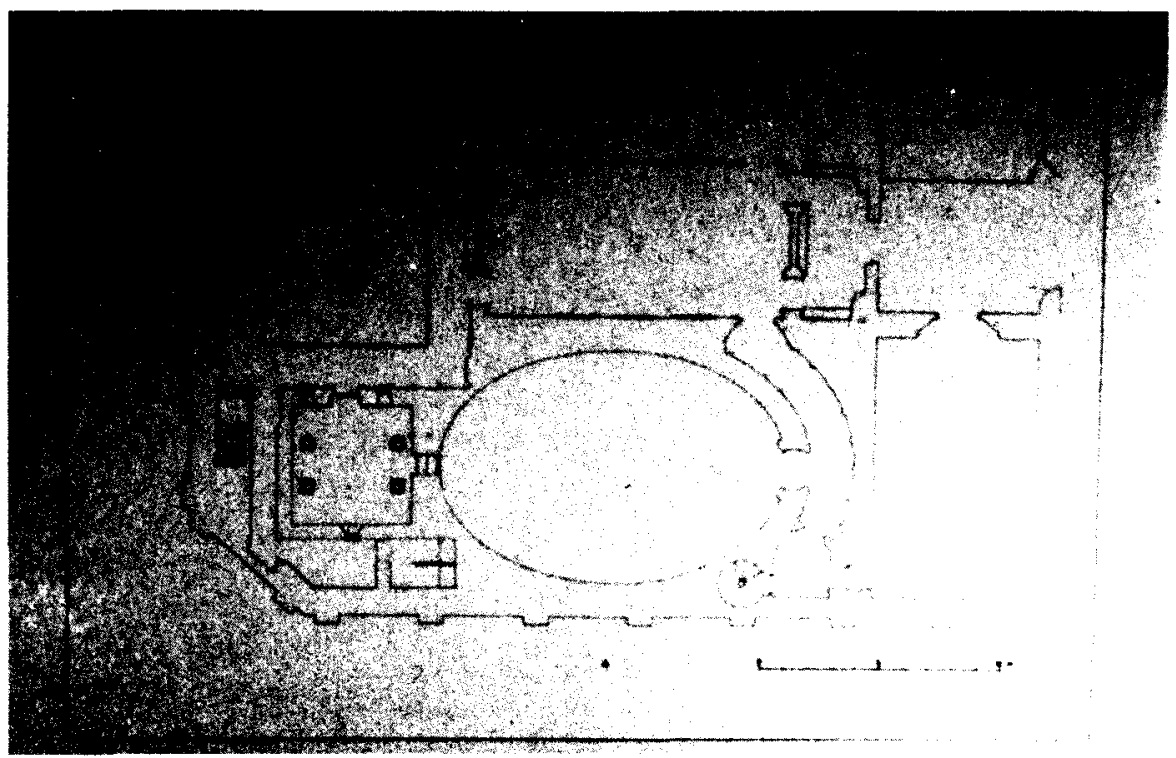

Fig. 7. Planta del conjunto de dependencias capitulares de la Catedral de Sevilla (A. Jiménez).

panillas, cuya construcción se prolongó prácticamente a lo largo de todo el siglo xVi; aquí, sucesiva (pero también en ocasiones simultáneamente) fueron levantándose en dirección oeste/este, la denominada Sacristía de los Cálices, la Sacristía Mayor y finalmente las estancias capitulares y la Casa de Cuentas. Muy diversas entre sí formal y espacialmente -desde el gótico final de la Sacristía de los Cálices al óvalo "manierista» de la Sala Capitular - todas las edificaciones, sin embargo, quedaron unificadas por un alto muro perimetral con apilastrado exterior. Estas pilastras sólo se corresponden con la articulación interior de la Sacristía Mayor, lo que induce a pensar que el muro se debió levantar al compás de ésta, prolongándose luego en ambas direcciones y delimitando en el extremo este (al menos en cimientos) un estrecho solar donde se levantarian las estancias capitulares que reclaman nuestra atención.

Las limitaciones impuestas por el solar preexistente constituyen un factor importante a la hora de enjuiciar estas estancias; en efecto, si estudiamos el plano de la zona, la imagen que se desprende es de un caótico assemblage de espacios, lleno de saltos de escala y sorpresas visuales (figs. 7, 8). Esta constatación nos obliga a plantearnos, a su vez, dos interrogantes: ¿pudo el conjunto de las estancias capitulares resultar de 


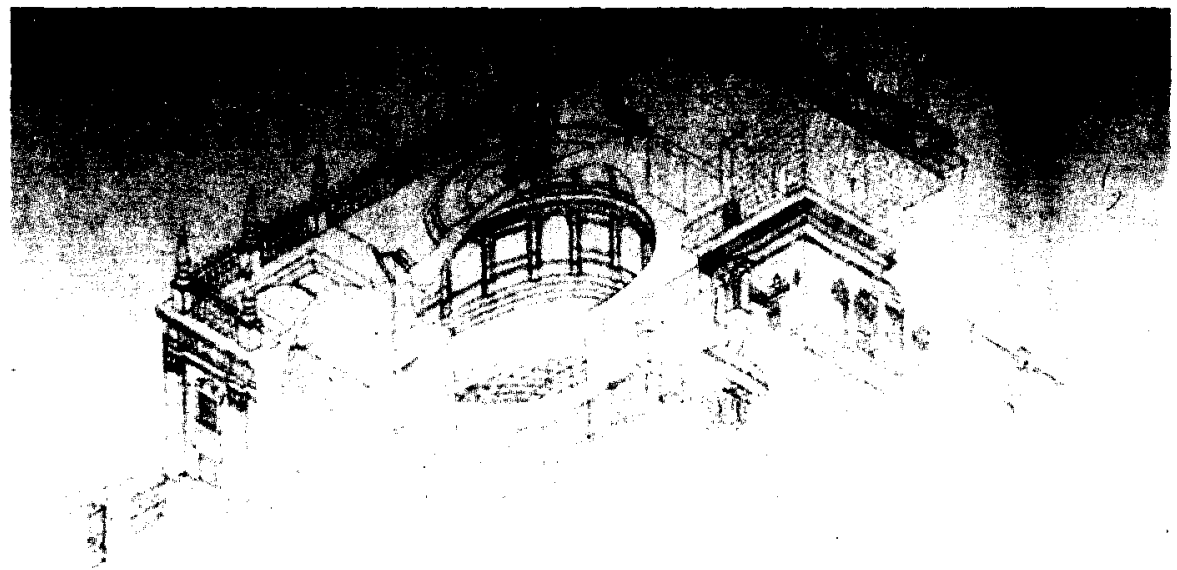

Fig. 8. Sección del conjunto de dependencias capitulares de la Catedral de Sevilla (A. Ampliato).

un proceso fragimentario, aditivo, fruto de la intervención de varios maestros? o bien, si aceptamos una paternidad única inos encontraríamos ante un ejemplo típico de scherzo minierista, destinado como diría Vasari del Palazzo del Té a abbagliare l'intelletto?

Antes de intentar responder a tales interrogantes conviene resumir los datos conocidos. Aunque la primera mención de una nueva sala capitular (distinta de la vieja, situada en el Corral de los Olmos) se remonta a 1528, cuando Diego de Riaño recibió de los canónigos 20 ducados upor las muestras que fizo e traças para la sacristía e cabildo e capillas del lado del coros ${ }^{18}$, lo cierto es que del capítulo no se hizo nada, con la posible excepción del muro perimetral o al menos sus cimientos. Es preciso esperar hasta 1558 , cuando los canónigos aprobaron las trazas para hacer el Cabildo y el modelo de la torre presentados por Hernán Ruiz, iniciándose la construcción el 17 de agosto de ese año ${ }^{19}$. A partir de entonces,

18 Gestoso, J., Sevilla Manumental y Artística. Sevilla 1892, vol. II, pág. 273.

19 JimÉnez, A., y CABEZA, J.M., Turris Fortissima. Documentos sobre la construcción, acrecentamiento y restauración de la Giralda. Sevilla 1988, pág. 211. 


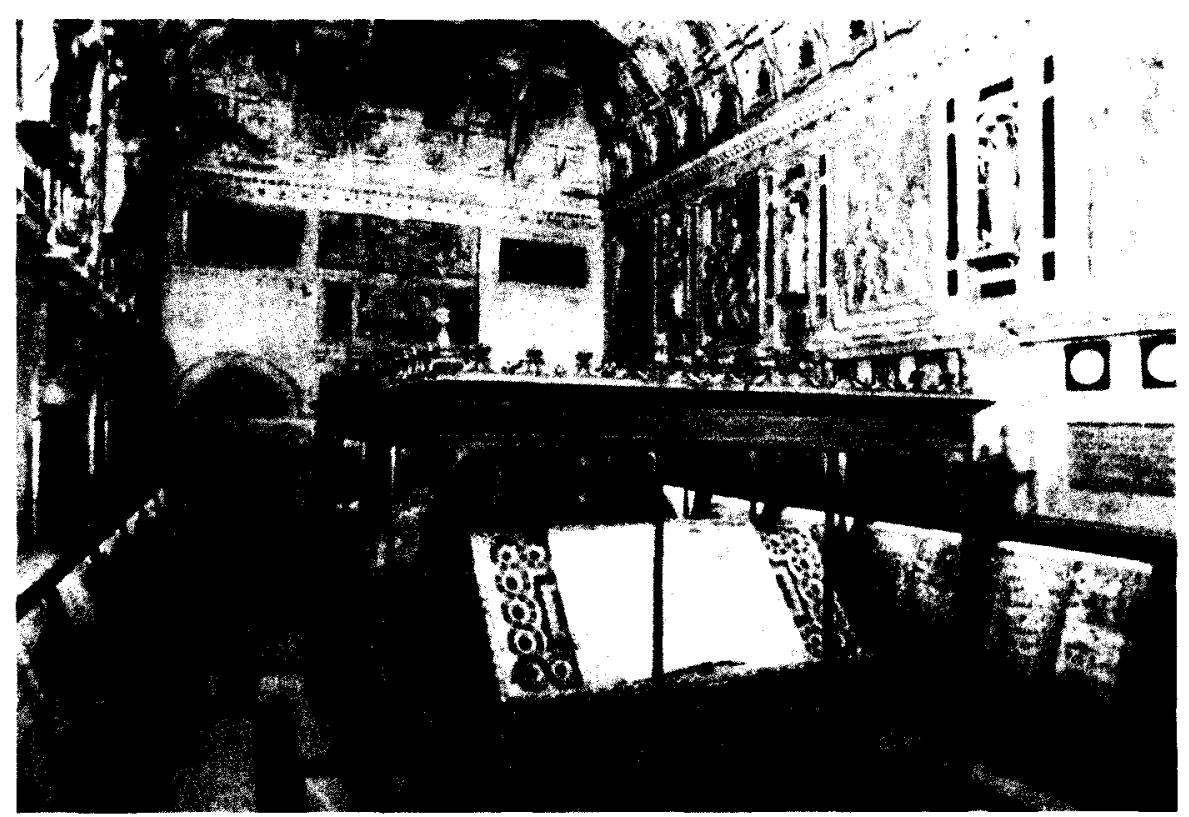

Fig. 9. Sala del Antecabildo. Catedral de Sevilla.

con alguna interrupción como la acaecida entre 1561 y 1568, las obras continuaron hasta su finalización en 1592, cuando por primera vez, el 11 de septiembre se reunieron los canónigos en el nuevo Cabildo. La muerte de Hernán Ruiz en 1569, por otra parte, supuso la intervención de una nutrida nómina de arquitectos, desde la consulta evacuada en 1571 por Valdelvira y Francisco del Castillo, al cierre de la antesala capitular en 1584 por Juan de Minjares ${ }^{20}$. Para juzgar el proceso de la obra resulta significativo un auto capitular de una fecha tan tardía como es el 18 de junio de 1586 donde se pide "que el Cabildo nuevo se vaya prossiguiendo con toda la priessa q. fuere posible "hasta acabar la cornisa..."” ${ }^{21}$.

Teniendo en cuenta tan accidentada historia ¿qué podemos considerar que permanece del proyecto primitivo de Hernán Ruiz? Es preciso interrogar una vez más el plano del conjunto. Desde hace tiempo se ha señalado la vocación de “romanidad» que se desprende de las estancias

${ }^{20}$ Cf. MORALES, A., "La arquitectura en los siglos XVI, xVII y XVIIl", en AA.VV., La Catedral de Sevilla. Sevilla 1984.

21 Gestoso, J., op. cit., vol., cit., pág. 389. 
capitulares (fig. 9), especialmente acusada en la propia Sala del Cabildo, cuyo pavimento copia el diseñado por Miguel Ángel para el Capitolio de Roma, quizás conocido por los grabados de Dúperac ${ }^{22}$ (fig. 10). Pero más allá de este detalle, el análisis del plano revela que la intención de Hernán Ruiz (en cuanto tracista de la obra) parece haber sido un intento de reconstrucción de la domus romana descrita por Vitrubio.

Si aceptamos esta hipótesis,el plano extrañamente descoyuntado del conjunto quedaría justificado por la necesidad de introducir dentro de unos estrechos limites los espacios constitutivos de la domus romana. En efecto, podemos identificar claramente la secuencia Antecabildo/Patio del Mariscal, con el Atrio Testudinato y el Cavedio Tuscanico descritos por el tratadista romano, siendo particularmente notable la similaritud entre el Patio del Mariscal y el cavedio sin soportes vitrubiano. De la misma manera parece clara la identificación entre la propia Sala Capitular y la Exedra amplis magnitudinis que Vitrubio señala como especialmente apropiada para reuniones numerosas, asi como la sala adyacente (sólo recientemente dibujada) articulada por cuatro columnas, con el Oecus Tetrastylus ${ }^{23}$.

Que Hernán Ruiz estuvo interesado en Vitrubio lo demuestran varios hechos: el más fehaciente, desde luego, su propia traducción parcial del texto vitrubiano que, como señala Navascués hay que situar entre 1550 y $1560^{24}$, es decir, justamente las fechas en las que el arquitecto elaboraba sus proyectos para la Catedral sevillana. Por otro lado, el segundo de los proyectos catedralicios de 1558 de Ruiz ha sido reciente y convicentemente interpretado por Nieto Alcaide como una versión de la Torre de los Vientos descrita por Vitrubio ${ }^{25}$. Tendríamos así entre ambos proyectos una estrecha afinidad basada en su común raíz vitrubiana, lo que constituye una experiencia "arqueolologizante» prácticamente sin precedentes en la España del Quinientos. Queda un extraño aspecto en la planta de las estancias capitulares que llama nuestra atención: el chaflán de esquina. Nada parece justificar este quiebro del lienzo, pues la muralla musulmana de la antigua alcazaba interior, que ha sido aducida como justificación, discurría en realidad casi adosada al muro de la "quibla" de

22 Cf. Lleó Cañal, V., "La Catedral en la historia de Sevilla", en AA.VV., La Catedral de Sevilla, cit.

${ }_{23}$ Cf. JIMÉNEZ, A., "Antecedentes formales del Oratorio de San Felipe Neri, Cádiz», en Boletín del Museo de Cádiz, IV, 1983-4.

24 Navascués, P., ed. El libro de arquitectura de Hernán Ruiz, el joven. Madrid 1974.

25 NiETO ALCAIDE, $V$., "El mito de la arquitectura árabe, lo imaginario y el sueño de la ciudad clásica", en Fragmentos 8 y 9, 1986. 


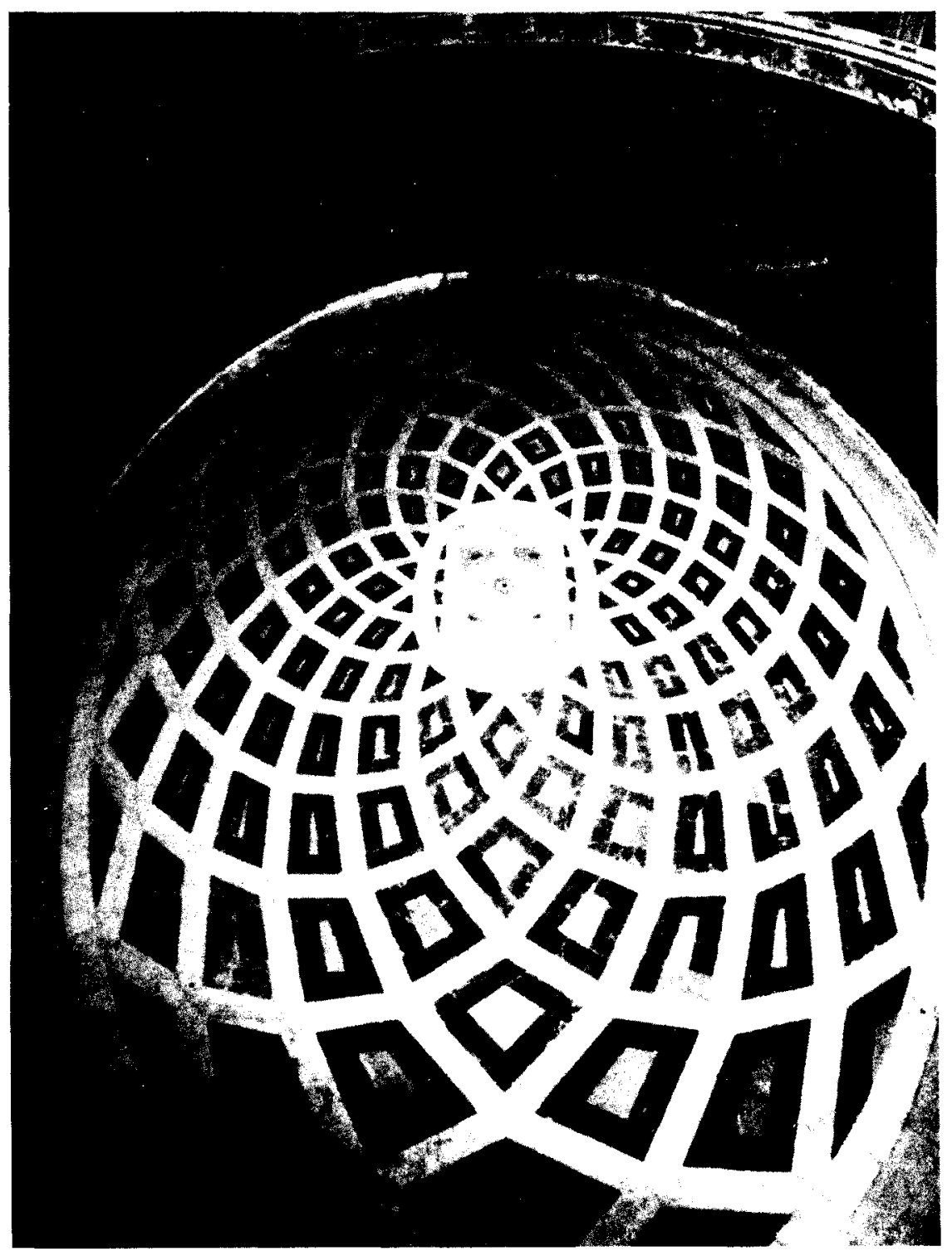

Fig. 10. Sala Capitular. Catedral de Sevilla. 
la primitiva mezquita y por lo tanto considerablemente retranqueada del punto donde se produce el quiebro y en cualquier caso la muralla fue demolida en $1485^{26}$. La única justificación que se nos ocurre para esta anomalía es que en ese chaflán, en algún momento, se hubiera pensado abrir una puerta para el arzobispo, independiente de la de los canónigos. Las relaciones entre los prelados y el cabildo catedralicio fueron frecuentemente tirantes a lo largo del siglo XVI, pero en 1556, ocupando la sede el Arzobispo D. Fernando de Valdés y a causa de la canongía de Constantino Ponce de la Fuente, la tensión alcanzó su punto más álgido ${ }^{27}$. En ese clima enrarecido no resulta difícil imaginar que el Cabildo aprobase un proyecto que subrayaba la simetría de poderes entre el arbispo y los capitulares, ocupando la puerta de cada uno un extremo del eje mayor en la Sala Capitular. Es posible que, a lo largo del accidentado proceso de ejecución de las estancias capitulares esta sutil alusión quedará relegada; sin embargo, no debió ser totalmente olvidada, pues un mes escaso antes de que fuera inaugurada la sala, en sesión del 12 de agosto de 1592, los canónigos decidieron que se abriera una puerta justo "detrás de la silla del perlado» ${ }^{28}$, que aún hoy se conserva.

Si nuestra interpretación de los planos fuera correcta, el proyecto de Hernán Ruiz se habría cumplido en sus aspectos esenciales, mientras que las intervenciones de otros arquitectos entre 1569 y 1592 habrían afectado sólo a aspectos decorativos o soluciones de cierre. Ello permitiría responder a la primera de las preguntas que nos formulábamos páginas atrás: el conjunto de las estancias capitulares, pese a su confusa apariencia, responde a un conjunto unitario, a un intento de reconstrucción de la domus vitrubiana, y consecuentemente a un solo autor, Hernán Ruiz. Por lo que respecta al supuesto juego "manierista" de sus espacios, cuando menos debemos preguntarnos si se trata de una virtuosista exhibición de sprezzatura o si, por el contrario, se debe a las dificultades inherentes a introducir en unos estrechos límites un programa sumamente complejo.

Pero en definitiva lo que más nos interesa es subrayar el carácter excepcional de este programa, que constituye una expresa declaración de fe en los valores clásicos; un programa en el que la arqueología, una vez más aparece no como una ciencia aséptica y neutral, sino como un vehículo de una concepción del mundo.

26 Cf. JIMÉNEZ A., “Análisis formal y desarrollo histórico de la Sevilla medieval", en La arquitectura de nuestra ciudad. Sevilla 1981

27 Cf. Menéndez y Pelayo, M., Historia de los Heterodoxos Españoles. Madrid 1967, vol. II, págs. 58 ss.

${ }_{28}$ Archivo de la Catedral de Sevilla, Autos Capitulares, 1592-3, fol. 32 v. ${ }^{\circ}$. 
